\title{
Improvements of Football Clubs' Marketing Strategies in Russian Reality
}

\author{
Dmitry Panferov, Alexander Averin \\ Financial University under the Government of the Russian Federation, Moscow, Russia
}

\begin{abstract}
ANNOTATION
The article examines the issues related to the marketing activities of Russian football clubs in order to identify patterns in this process, as well as assessing the prospects for an integrated approach to evaluating such strategies in modern conditions, in particular, solving the issue of maximizing the effectiveness or efficiency and increasing the attractiveness of Russian football clubs in the international arena. The purpose of this study was to investigate how Russian football clubs deal with marketing activities in the new reality and consider the ways of optimizing their work. It can be concluded that a marketing strategy is necessary for every football club since it can be used not only to generate new ways of interacting with stakeholders, but also to create a good idea of the brand and ensure its promotion with much lower costs and problems, and also to evaluate the effectiveness of brand communications.
\end{abstract}

Keywords: football, marketing, integrated approach.

\section{INTRODUCTION}

The problem of the study and the degree of study. In recent years (especially before the World Cup in Russia), there has been a clear tendency towards the desire of government bodies to contribute in every way to the development of various sectors of the economy, including the sports (football) sphere, but the main driver for the development of companies in this area remains club managers who, with the help of financial, investment and, above all, marketing tools, solve a range of issues regarding the promotion of a football club brand in the external environment.

Therefore, it is the actions of specific specialists that largely determine how exactly a football club positions itself in the external environment, and also with the help of which tools it solves the problems of increasing the brand's popularity and attracting fans to stadiums, which directly contribute to the increase in sales of related products to clubs. Marketing management in a football club as well as in companies of other industries should be based on a marketing strategy that should solve a number of specific issues and ensure that the football club is stable in the external environment even in times of crisis. In this regard, the relevance of theoretical and practical research of this problem cannot be questionable.

The purpose of this study was to investigate how Russian football clubs deal with marketing activities in the new reality and consider the ways of optimizing their work.

The object of research was marketing strategies.

\section{RESEARCH METHODS}

Methods. Given the practical nature of the purpose of our analysis, the literature review method was considered the most suitable for the study. Its main goal was to identify patterns, gaps and problems of existing theories and concepts in the field of evaluating the effectiveness of marketing strategies of football clubs, as well as to develop recommendations for further research through a critical and constructive analysis of the existing ones in a specific area of knowledge.

To overcome obstacles and limitations associated with a small (relative to other subject areas) 
number of published studies, differences in their quality, the principle of a systematic review was developed, aiming at minimizing subjectivity in evaluating certain literary sources, as well as increasing the likelihood of identifying areas for further research.

Based on the general analysis of the problem of the absence of applicable integral indicators for assessing the effectiveness of marketing strategies of football clubs in terms of maximizing utility, the article poses research questions to clarify the basic directions for implementing marketing strategies and its main principles, and also provides a primary assessment of the prospects of an integral approach to such an assessment.

Organization of the study. The reference search set includes the following combinations of the main keywords in English: "efficiency" + "marketing strategy", "integral approach" + "football clubs' strategy", "measuring performance" + "football clubs", "integrated marketing" + "Football clubs".

Searches of the Web of Science, eLibrary, Cyberleninka, Scopus, and ResearchGate databases were limited to randomized control trials. After conducting a keyword search, we got over 1000 links. Therefore, we had to limit the literature review process to those areas that are consistent with our research questions, namely marketing strategy and analysis of its effectiveness.

Based on the fact that the purpose of the study is to identify the latest trends in this area, we mainly consider articles published in English and Russian in the period 2012-2019. As a result of the search, a list of all topics that meet our requirements was generated. We selected 22 out of 124 articles that most accurately reflect the subject of the study. The conclusions and generalizations presented below are formed through a critical analysis of these materials.

Modern economic reality has a significant impact on the football business, and it covers not only large and well-known clubs that operate on the market for a long time, but also newly formed teams whose life expectancy does not exceed five years.

\section{RESEARCH RESULTS}

Theoretical studies in the field of marketing strategies of football clubs and methods for their optimization have been conducted not so long ago, however, in recent years, many Russian and foreign scientists have spoken on this subject. In particular, this topic was covered by N. A. Osokin (2017), I. V. Solntsev (2018), V. V. Galkin (2009), A. Andrikopoulos, N. Kaimenakis (2009), D. Plumley et al. (2017), D. Maderer, D. Holtbrügge (2018), A. E. Manoli (2018) and some others.

However, despite a rather deep study of many aspects of the marketing component in the system of strategies of football clubs, some issues still remain uncovered. So, for instance, there is no clear understanding of exact indicators to evaluate the effectiveness of the implementation of marketing strategies of football clubs.

In addition, there is no single and universally accepted definition of a football club's marketing strategy, which, firstly, does not allow us to understand with certainty which aspects of the club's marketing activities it should reflect, and secondly, using which methods it should be developed. For the development of marketing science in the field of sports in this projection, it is necessary to create methodological recommendations or field-proven assessment methods that comprehensively consider both quantitative and qualitative characteristics of the club, which should be paid attention to when 
creating, applying and introducing transformations into a marketing strategy.

All this reflects the need for continuous updating of theoretical provisions on ways to improve the marketing strategies of football clubs.

The marketing strategies of football clubs are a substance, of course, important and worth the attention of many researchers. This is due to the fact that in the modern digital era, it is the marketing component of sports organizations that comes to the fore. It does not really matter how many trophies the club wins in a season, it is much more important how many new fans it attracts to the stadium and how much it expands its fan base.

By the name of the topic itself, it can be concluded that something is not quite right with the marketing strategies of football clubs. Otherwise, in the title of the topic there would be no collocation of the path of improvement. Of course, football clubs have marketing strategies, and they even spent or are currently spending a lot of money on them. It is quite another matter that this money was received in an insufficient volume and not from the most market sources. Simply put and quoting the words of the RFU digital director and Soft sport co-founder, Ivan Ryndin, "Sports marketing in Russia today is underfunded, not everyone understands the value of this area - or realizing that the result will not come quickly, focus on more clear and linear development issues: buy / sell players, arrange financing with the regional authorities for the next season. If you take the average on the market, then sometimes all matters in the information environment, starting from the minutes of matches and working with journalists and ending with SMM and shooting videos, is engaged in the press attache in the singular. Everything else is a consequence of this situation. I do not want to talk about the special path of Russia. But the lack of market conditions for clubs and a lack of understanding of the importance of working with the audience leads to what we see now - interest in sports as a whole is far from its great potential" (Garanina, 2018).

As mentioned above, marketing management in a football club, as well as in companies of other industries, should be based on a marketing strategy, and in a sports environment, it should be focused on solving issues related to:

- production and sale of souvenirs, paraphernalia and other branded things;

- coordination of relations with sponsors, conclusion of contracts with them, as well as their involvement in events held by the club;

- managing the commercial capabilities of sports facilities that are controlled or entrusted to a football club;

- management of advertising, PR and interaction with various media resources;

- sale of rights to television, radio and Internet broadcasts;

- implementation of digital projects on the Internet (Galkin, 2009).

The complex of issues under consideration is not comprehensive and can be supplemented in connection with the country-specific features of the football club, as well as modified based on the ownership structure and a number of other factors (Solntsev, 2018).

A modern football club can be compared for a long time not only with a global corporation, but also with a large media company that produces specialized content (a sports spectacle and its surrounding components), and increases the audience due to its quality and quantity, as well as the sports results of the club teams. Moreover, trends show that sports results do not always occupy a dominant position 
(Costa et al., 2018).

At the same time, football clubs monetize the audience in three main ways: through the sale of TV rights, through sponsorship (the larger the fan base, the higher the popularity of the club, the more, all other things being equal, the investments of the club's sponsors), as well as through the sale of merchandise related to the club (mainly on match day).

The allocation of these sources to the main revenue components of football clubs is classically accepted, however, the proportional separation varies significantly depending on the country in which the football club operates. If we take Europe into consideration, significant source of income for football clubs is income from the sale of broadcasts. For stably developing clubs, the rate of $30-40 \%$ is normal, but in some countries this amount allows for 50-70\% coverage of the club's annual budget (Fig. 1).

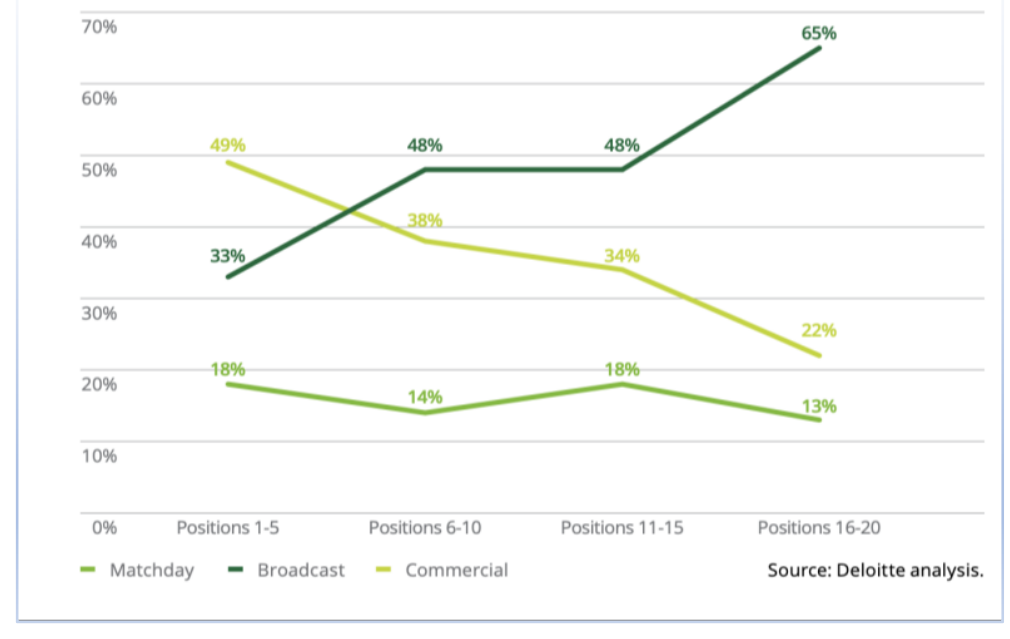

Figure 1. Football club's income distribution chart by category (Ajadi et al., 2020)

Extremely high dependence on funds received by clubs from selling television rights can lead to collapses in a difficult economic environment, for instance, associated with the coronavirus pandemic in 2020. For example, 13 clubs of the German Bundesliga simply could not help but resume their performances this season, as otherwise they would have lost their livelihoods.

Over the past five years, a situation has persisted in Russian football when clubs receive less than $5 \%$ of their income from the sale of television rights, which is also an extremely unhealthy situation. On the one hand, there is no need to talk about any kind of dependence, however, one cannot speak of a normal (in comparison with European counterparts) income level in a normal economic situation. The state character of the main RPL broadcaster of the Match TV channel, which essentially owns a monopoly on display, which means it dictates prices and, together with them, the club's revenues, is to blame for the state (Panferov, 2019 a, 2019 b). Sponsorship revenues are extremely important for keeping Russian football clubs on the brink of survival. The fact is that, contrary to the logic of market functioning, these cash flows account for approximately $50 \%$ of the income of football clubs, while in European analogues this percentage barely exceeds $10-15 \%$ (Solntsev, 2018).

As for the third component of the income of the football club, the revenue on the day of the match is formed due to the physical number of people in the stadiums. The principle of direct dependence works: the more people visit the stadium on the day of the match, the more revenue will be. Russian 
clubs have the potential for increasing match day incomes, and it is based on two key positions: ultramodern stadiums appeared in Russia after the 2018 World Cup, as well as increased general interest in football, which is confirmed by the statistics in Figure 2.

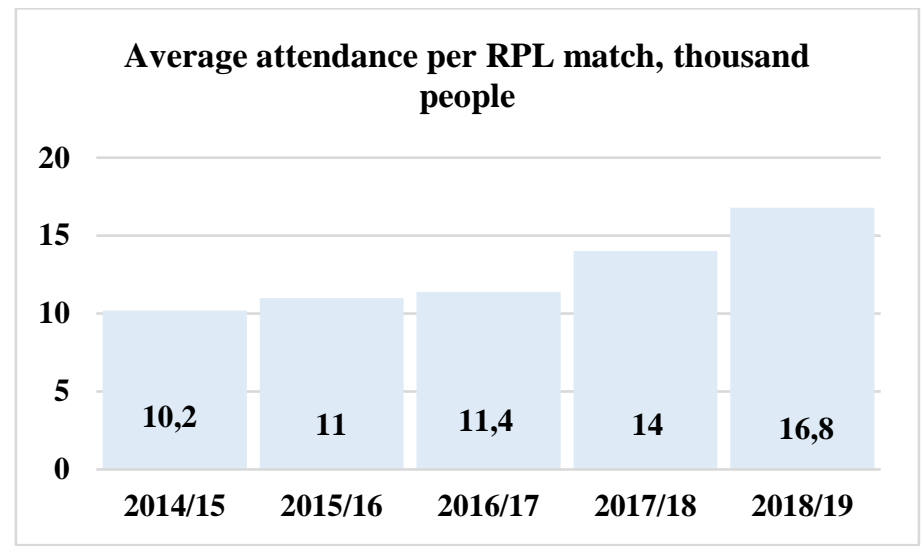

Figure 2. Attendance of RPL club stadiums (Malyshev et al., 2019)

The data allow us to conclude that Russian football clubs have the potential to reduce the share of sponsorship revenues in the budget, as they can take full advantage of new or updated stadiums and increase revenue through their competent use. As mentioned above, in Russia, most of the income of football clubs is commercial income, which should reflect the success of the club's marketing strategy, but in Russian practice include sponsorship funds. But this is a misconception: the largest share in sponsorship revenue is held by money received outside the competitive market. That is, clubs receive banal subsidies from the state and state companies (more than $75 \%$ of Russian football clubs in Russia live like this) or from sponsors of a different order.

However, despite all the disadvantages, Russian football clubs over the past year have shown positive dynamics in the field of commercialization of their brands and monetization of spectator interest (Fig. 3).

\begin{tabular}{|c|c|c|}
\hline Services for fans on match day & Active clubs (2018/19) & Active clubs (2019/20) \\
\hline Attribute sales points in the stadium & 15 & 16 \\
\hline Entertainment before the match / during the break & 14 & 15 \\
\hline Sponsored entertainment venues & 13 & 14 \\
\hline Children / family sector & 12 & 13 \\
\hline Special mode of operation of public transport & 6 & 9 \\
\hline Discounts and preferences for taxis for fans & 2 & 1 \\
\hline Specialized services for people with disabilities in the stadium & 0 & 11 \\
\hline Children's room during the match & 0 & 7 \\
\hline Viewing away matches at the stadium & 0 & 3 \\
\hline
\end{tabular}

Figure 3. Marketing activities of Russian football clubs (Malyshev et al., 2020)

So, for instance, $100 \%$ of clubs organized paraphernalia selling points in stadiums. A slightly smaller part organizes entertainment events before the matches (the main example is FC Lokomotiv), sponsor entertainment venues, and also forms specialized children's and family sectors. 
To a much lesser extent, clubs are actively working with transport infrastructure on the day of the match. A special order of public transport was recorded in the 2019/20 season in only 9 out of 16 clubs, and only one club provided discounts on taxis for fans. So, the prerequisites for the fact that changes in the marketing strategies of Russian football clubs are necessary, obvious and understandable: there is still an irrational revenue structure, dependence on sponsors, lack of an integrated approach to the implementation and evaluation of marketing activities. In this regard, I developed a concept of a possible structure for the marketing strategy of a football club, which will ensure the integrated character of brand formation in the external environment. Marketing activations were offered in 4 blocks: general, digital, IT and match day.

Within the framework of the general block, it is proposed to focus on the following main points. Firstly, Russian clubs should strive for cross-country communications, greater integration in world football and an increase in the fan base abroad. For this, the marketing teams of clubs should take care of at least the international official website and the maintenance of social networks in foreign languages. In Russia, an excellent example of such an international focus can be considered the champion of Russia, "Zenit", whose website has 13 languages, and social networks are conducted in at least 4 languages (Russian, English, Spanish, German). The struggling "Zenit" for the title of the most popular club in Russia «Spartak» on the site, there are only 3 languages (Russian, English, Chinese).

As for the second component of the general block, it is worth saying that football clubs, albeit historically different, are gradually moving away from the concept of maximizing utility (winning trophies) as an exceptional goal and turn their eyes to maximizing profits. It is quite obvious that with a huge variation in financial opportunities, a separate pool of teams, which includes from 30 to 50 clubs, can claim for a championship within countries, as well as a successful performance in the largest European tournaments. What remains of the rest? Understanding that to achieve material success in the form of cups in a club museum is quite difficult, they need to modify and focus their activities on the development of the club as a financial enterprise. And if there are sufficient volumes of financial resources, then strive to succeed both in that and in another (Osokin, 2017). The next key point in the general block is the use of money from sponsors on the principles of borrowed capital. Firstly, lending principles will allow clubs to be more focused on increasing the profitability of investments received. This will make them more disciplined. Secondly, it will allow to concentrate efforts on other sources of earnings in a competitive market. And they can be much larger if used correctly. And finally, the brand of a football club in the 21 st century should be based on the main trends: the dissemination of social values and personalization of the club for each fan.

As for the second system unit of the structure, these are IT solutions. The prospects of IToptimization of processes are based on the active use of CRM-systems based on the analysis of big data. They give football clubs the opportunity to significantly increase not only the revenue from ticket sales, but also to commercialize the brand. For instance, the football "Zenit" in the season 2018/19 using the CRM system attracted more than a million fans to the stadium per season and increased the effectiveness of advertising campaigns by $27 \%$. Moreover, the club managed to significantly increase the rate of openness of letters and with the benefit of the fans to transfer almost all communication to online (Васильев, 2019). An equally important element of any marketing strategy should be digital activation. 
It is hardly worth explaining their importance, because each club of the Russian Premier League has a rather substantial presence on social networks, but the situation in the lower divisions is much worse. It would seem that it is at the regional level that fan movements can be formed on the principles of support your local team, however, residents of cities where FNL and PFL clubs are present hardly know much about the clubs that represent these cities (Fig. 4).

\begin{tabular}{|c|c|c|c|c|c|c|}
\hline № & Din. & Club & Rating & Site & \multicolumn{2}{|r|}{ Social Networks } \\
\hline 1 & - & Zenit & 83,7 & fc-zenit.ru & \multicolumn{2}{|c|}{$f \mathrm{k} v$ 웅 $0 \pi$} \\
\hline 2 & $\uparrow$ & CSKA & 82 & pfc-cska.com & \multicolumn{2}{|c|}{ f $\mathbf{x}$ : 0} \\
\hline 3 & P & Lokomotiv & 81,7 & folm.ru & \multicolumn{2}{|c|}{ 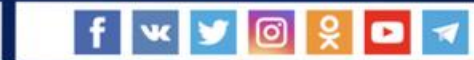 } \\
\hline 4 & $\checkmark$ & Spartak & 78,5 & spartak.com & \multicolumn{2}{|c|}{ f $x y$ 园 } \\
\hline 5 & $\checkmark$ & Krasnodar & 78,4 & fckrasnodar,ru & \multicolumn{2}{|c|}{$f w y$ 回这 } \\
\hline 6 & $\uparrow$ & Dynamo & 77,6 & fcdynamoru & \multicolumn{2}{|c|}{ f $v$ y } \\
\hline 7 & - & Rubin & 76,8 & rubin-kazan.ru & \multicolumn{2}{|c|}{ 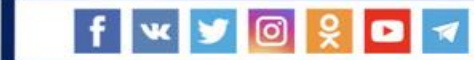 } \\
\hline 8 & $\uparrow$ & Ural & 75,1 & fc-ural.ru & \multicolumn{2}{|c|}{$f u v$ 回 } \\
\hline 9 & $\uparrow$ & Krylja Sovetov & 72 & kc-camapa.ru & \multicolumn{2}{|c|}{$f \mathrm{k} y$ 目园 } \\
\hline 10 & $\downarrow$ & Anji & 71,7 & fc-anji.ru & \multicolumn{2}{|c|}{ f $\mathrm{x} y$ 웃ㅁ } \\
\hline № & Din. & \multicolumn{2}{|c|}{ Club } & Rating & Site & Social Networks \\
\hline 75 & $\downarrow$ & \multicolumn{2}{|c|}{ Murom } & 21 & fe-muromru & мy圆口 \\
\hline 76 & $\uparrow$ & \multicolumn{2}{|c|}{ Zenit (Izhevsk) } & 18,3 & zenit-zhevskk.ru & 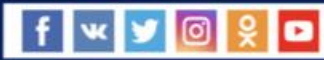 \\
\hline 77 & $\uparrow$ & \multicolumn{2}{|c|}{ Khimik } & 17,4 & fchimikru & $\mathrm{s}$ 圆 \\
\hline 78 & - & \multicolumn{2}{|c|}{ Kvant } & 17,2 & kvantfutbol & $f k y$ 园送 \\
\hline 79 & $\downarrow$ & \multicolumn{2}{|c|}{ Pskov-747 } & 11,9 & pskov-747.ru & f $\mathrm{k}$ y \\
\hline 80 & $\uparrow$ & \multicolumn{2}{|c|}{ Kolomna } & 10,2 & kolomna-fc.ru & $\mathrm{k}=0$ \\
\hline 81 & $\downarrow$ & \multicolumn{2}{|c|}{ Enrgomash } & 10,2 & фк-энергомаш.рф & $\mathrm{k}=0$ \\
\hline 82 & $\uparrow$ & Zork & & 9,6 & fczorky.ru & $f \mathrm{k} D$ \\
\hline 83 & $\downarrow$ & Biolog-Nov & & 8,1 & fc-biologru & $\times 0$ \\
\hline 84 & $\downarrow$ & Angu & & 8 & fc-angushtru & f $\mathbf{x}$ 임 \\
\hline 85 & $\downarrow$ & Spartak (K & & 0,9 & spartak-ks.ru & f м \\
\hline
\end{tabular}

Figure 4. Digital rating of Russian football clubs in the 2018/19 season (Хасанова, 2019)

Finally, the fourth and final building block. It is about optimizing the use of sports facilities on match day. Successful European clubs receive up to $20 \%$ of annual revenue from match day events, while Russian clubs have a record for the entire history of the league that does not exceed $8 \%$. 
In my opinion, the most optimal scenario for the development of communication with the audience is FC Lyon, which, since the stadium was commissioned, began to actively use the areas around and in the stadium to actively promote event marketing events. The club decided to divide the territory around the stadium into different zones, conduct weddings at the stadium, arrange quests and use other opportunities to earn money. And the result had been appeared quickly. The total attendance growth of the stadium for 2 years amounted to $30 \%$, the club showed a $15 \%$ increase in revenue, and also increased revenues from events not related to football by $61 \%$. Ticket revenues, as a side measure, jumped $60 \%$. Russian football clubs, as mentioned above, have excellent potential for the development of similar event-strategies (new stadiums and their insufficient occupancy). So, Russian clubs have prospects for the future - all that remains is to make this future rich and profitable.

In conclusion, it is worth noting that the situation with the marketing strategies of Russian football clubs is rather ambiguous. It is clear that in the public domain, it is not possible to find data that exactly tells how much marketing is financed, but a general understanding of the situation develops without any problems. Based on the reports of audit and analytical agencies, we can conclude that the clubs began to realize that focusing only on sports results will bring results in far from $100 \%$ of cases. In this regard, many teams began to move towards strengthening the marketing presence not only on match days, but also in everyday life, providing a comprehensive and systematic approach.

\section{DISCUSSION}

Realizing that organizational efficiency and effectiveness to a large extent depends not only on titles won, but also on financial performance, fan base growth, as well as the number of followers in social networks, which then turn into loyal fans, we can conclude that for a correct and adequate assessment of the club's marketing strategy and its overall activities requires a system that will take into account these, as well as unnamed, but no less important, indicators.

In the developments of modern foreign and domestic researchers, there are postulates on how, in principle, to approach the assessment of effectiveness. One approach suggests looking at four groups of indicators: sports performance, media, fans, and stakeholders (Andrikopoulos, Kaimenakis, 2009). Another focuses on the use of sports, financial and social metrics (Dima, Otoiu, 2015). However, in my opinion, the most systematic approach to assessing the effectiveness of football has become a comprehensive analysis of sports and financial indicators (increase in turnover, profit, ROCE, current liquidity ratio, debt level, financial leverage, share of salary in turnover, percentage of victories, points in the championship, average stadium occupancy) proposed by Plumley, Wilson and Ramchandani (Plumley et al., 2017). It is their development that will be used for adaptation when creating your own system for evaluating the effectiveness of a marketing strategy.

\section{CONCLUSIONS}

A possible option for optimizing marketing strategies was proposed in the work. Even for those that are developed quite comprehensively (it is not possible to find out because of trade secrets). The structuring mechanism was developed with the condition of further development of a system for evaluating the marketing strategies of football clubs. It also monitored the pattern in which clubs should 
choose integrated marketing strategies for internationalization, personalization and digitalization for further growth. It was revealed that the reason for this is that in the domestic market clubs have mastered relatively well, and now they can direct their efforts to increase the number of fans in other countries, and subsequently, through marketing activities, monetize them.

All this allows us to conclude that the concept of the integration and complexity of the marketing strategy implies the understanding that a football club as an organization, in addition to functioning under conditions of interaction with macro elements (demographic, socio-cultural, political, technological factors), the state of the economy, international events) and microenvironments (customers (fans); suppliers (club academies and other football clubs preparing players, manufacturers of equipment and sports equipment); competitors) are also subject to the principle of mutual influence with them. So, one of the main stakeholders of the football club is the fans. Their participation in creating value is an extremely important topic in the approaches and methods of sports marketing, which means that the leaders of professional football clubs need to identify and use various areas of communication to develop relations with their fans.

Active development of new technologies and communication channels between clubs and their potential customers constitutes a positive context for the development of football marketing. With their help, you can not only generate new ways of interaction, but also with much lower costs and problems, create a good picture of the brand, ensure its promotion, and also evaluate the effectiveness of the marketing strategy.

Based on the research, it is necessary to understand that the marketing strategy of a football club can significantly facilitate its task of increasing material well-being, as well as provide audience growth in the stands and brand recognition not only in the territory of a particular country, but also beyond its borders.

\section{REFERENCES}

1. Ajadi, T., Burton, Z., Dwyer, M., Hammond, T., Ross, C. (2020). Eye on the Prize: Football Money League [online]. Internet link: https://www2.deloitte.com/uk/en/pages/sports-business-group/articles/deloitte-football-moneyleague.html [Accessed on 2605 2020].

2. Andrikopoulos, A., Kaimenakis, N. (2009). Introducing FOrNeX: A composite index for the intangible resources of the football club. International Journal of Sport Management and Marketing, 5 (3), 251-266.

3. Costa, M. F. D., Costa, C. E., Angelo, C. F. D., Moraes, W. F. A. D. (2018). Perceived competitive advantage of soccer clubs: A study based on the resource-based view. RAUSP Management Journal, 53 (1), 23-34.

4. Dima, T., Otoiu A. (2015). A Composite Index to Assess the Top European Football Clubs In 2014. Revista Economicăa, 67 (2), 68-85.

5. Galkin, V. V. (2009). Economics of Sports and Sports Business. Moscow: Knorus.

6. Garanina, Е. (2018). Современный футбольный клуб - это медиакомпания. A modern football club is a media company. Internet link: https://rb.ru/longread/digital-sport/ [Accessed on 2705 2020].

7. Maderer, D., Holtbrügge, D. (2018). International activities of football clubs, fan attitudes, and brand loyalty. Journal of Brand Management, 26 (4), 410-425. 
8. Malyshev, O., Kardash, A., Shalimova, A. (2020). PwC, Russian Premier League. Comprehensive study of the economics of Russian football. Season 2019/20. Internet link: https://www.pwc.ru/ru/publications/rpl-research-season1920.html [Accessed on 2705 2020].

9. Malyshev, O., Kardash, A., Shalimova, A. (2019). Russian Premier League. A Comprehensive Study of the Economics of Russian Football (Season - 2018/2019). Internet link: https://www.pwc.ru/ru/publications/rpl-research-season1819.html [Accessed on 2705 2020].

10. Manoli, A. E. (2018). Sport marketing's past, present and future; an introduction to the special issue on contemporary issues in sports marketing. Journal of Strategic Marketing, 26 (1), 1-5.

11. Osokin, N. A. (2017). Determinants of organizational performance of football clubs. Strategic Decisions and Risk Management, 4-5, 98-109.

12. Panferov, D. D. (2019a). Analysis of the financing of football clubs in Russia and its features in the context of digitalization of the economy. Uchenye Zapiski Rossiiskoi Akademii predprinimatelstva, 18 (1), 149-160.

13. Panferov, D. D. (2019b). Analysis of the financing of football clubs in Russia in the context of the digitalization of the economy. Actual Problems of Modern Financial Science, 74-78.

14. Plumley, D., Wilson, R., Ramchandani, G. (2017). Towards a model for measuring holistic performance of professional Football clubs. Soccer \& Society, 18 (1), 16-29.

15. Solntsev, I. V. (2018). Разработка унифицированного подхода к оценке стоимости футбольных клубов (Developing a Unified Approach for Evaluation of Football Club). Journal of Corporate Finance Research, 12 (1), 77 90.

16. Васильев, А. (2019). Zenit Knows Everything about the Habits of Fans: Numbers, Automation, Personalization. Project details with SAP. Internet link: http://sport-connect.ru/interview/zenit-sap [Accessed on 2705 2020].

17. Хасанова, Н. (2019). Обзор Digital Sports Rating. Internet link: https://weekendagency.ru/dsr [Accessed on $27052020]$.

\title{
Improvements of Football Clubs' Marketing Strategies in Russian Reality
}

\section{Panferov Dmitry, Averin Alexander}

Financial University under the Government of the Russian Federation, Moscow, Russia

\begin{abstract}
Relevance and novelty. The article examines the issues related to the marketing activities of Russian football clubs in order to identify patterns in this process, as well as assessing the prospects for an integrated approach to evaluating such strategies in modern conditions, in particular, solving the issue of maximizing the effectiveness or efficiency and increasing the attractiveness of Russian football clubs in the international arena.

Justification for the study. Therefore, it is the actions of specific specialists that largely determine how exactly a football club positions itself in the external environment, and also with the help of which tools it solves the problems of increasing the brand's popularity and attracting fans to stadiums, which directly contribute to the increase in sales of related products to clubs. Marketing management in a football club as well as in companies of other industries should be based on a marketing strategy that should solve a number of specific issues and ensure that the football club is stable in the external environment even in times of crisis. In this regard, the relevance of theoretical and practical research of this problem cannot be questionable.
\end{abstract}

The purpose of this study was to investigate how Russian football clubs deal with marketing activities in the new reality and consider the ways of optimizing their work.

Methods. The main research methods were literary review, analysis and synthesis of information, modeling and 
statistical analysis.

Results. As a result of the work, it was concluded that a marketing strategy is necessary for every football club, since it can be used not only to generate new ways of interacting with stakeholders, but also to create a good idea of the brand and ensure its promotion with much lower costs and problems. and also evaluate the effectiveness of brand communications. Realizing that organizational efficiency and effectiveness to a large extent depends not only on titles won, but also on financial performance, fan base growth, as well as the number of followers in social networks, which then turn into loyal fans, we can conclude that for a correct and adequate assessment of the club's marketing strategy and its overall activities requires a system that will consider these, as well as unnamed, but no less important, indicators.

Conclusion. Based on the research, it is necessary to understand that the marketing strategy of a football club can significantly facilitate its task of increasing material well-being, as well as provide audience growth in the stands and brand recognition not only in the territory of a particular country, but also beyond its borders.

Keywords: football, marketing, integrated approach. 